\title{
PECULIARITIES OF DETERMINING THE GASTRIC ACID SECRETION AND DIABETIC AUTONOMIC NEUROPATHY IN PATIENTS WITH CHRONIC PANCREATITIS AND TYPE 2 DIABETES
}

DOI: 10.36740/WLek202104132

\author{
Yelyzaveta S. Sirchak, Vasilij Ye. Barani, Olena M. Odoshevska, Oksana I. Petrichko \\ UZHHOROD NATIONAL UNIVERSITY, UZHHOROD, UKRAINE
}

\begin{abstract}
The aim: Is to determine the peculiarities of changes in the gastric acid secretion against the background of diabetic autonomic neuropathy and autonomic dysfunction in patients with chronic pancreatitis (CP) and type 2 diabetes (T2DM).

Materials and methods: We investigated 64 patients with CP and T2DM, who were included in the first group of the patients examined; Group II consisted of 40 patients with T2DM; and Group III of the patients examined consisted of 34 patients with CP.

Results: Differences were found in assessing the degree of autonomic nervous system (ANS) dysfunction in the examined patients, namely - the most pronounced ANS dysfunction according to the Wayne questionnaire was diagnosed in patients Group I, while patients of Group III. Analysis of gastric acid secretion indicates that no patients of Group III had normal acidity. Normal acidity is more often found in the second group of subjects. Both in patients with CP and T2DM, and in isolation with CP, moderate hyperacidity was more often determined.

Conclusions: The predominance of the parasympathetic division of the ANS, as well as manifestations of severe ANS dysfunction, are observed in patients with CP and T2DM. The prevalence of gastric hyperacidity on the background of DAN was established in patients with CP and T2DM. In this case, the absence of clinical symptoms or their minimal severity is determined, which indicates the lesion of the digestive tract in these patients.
\end{abstract}

KEY WORDS: chronic pancreatitis, type 2 diabetes mellitus, diabetic autonomic neuropathy, autonomic dysfunction, gastric acid secretion of the stomach

Wiad Lek. 2021;74(4):981-985

\section{INTRODUCTION}

Diabetes mellitus (DM) is a specific disease, on the background of which there has been an increase in comorbid pathologies in the recent years. Diabetes accounts for disruption of all types of substances of metabolism and affects all organs and systems of the body including the digestive system (esophagus, stomach, intestine, liver and pancreas) [1]. Of particular interest is the study of the combined course of chronic pancreatitis $(\mathrm{CP})$ and diabetes (DM) simultaneously affecting two different functions of the same organ $[2,3]$.

Chronic pancreatitis (CP) is one of the most complex polyethiological and polymorbid diseases [4]. The summation and potentiation of adverse effects of risk factors and the action of etiological factor of CP contribute to the growth of its incidence rate and progressive course, with exocrine insufficiency of the pancreas, development of maldigestion, malabsorption and trophological insufficiency in patients with impaired metabolism of all substances $[5,6]$.

Failure of the autonomic nervous system, i.e. diabetic autonomic neuropathy (DAN) is a serious and common complication that is observed in $16.8-54.0 \%$ of DM patients. However, DAN remains among the least studied complications due to its long asymptomatic course. It is often diagnosed late, and therefore difficult to treat due insufficiently developed methods of early diagnosis and treatment. Diabetic autonomic gastrointestinal neuropathy, with its characteristic gastroparesis, enteropathy and cholecystoparesis, is one of the main causes of labile course of the disease. It also increases the risk of gallstone disease 2-5 times in patients with DM compared to the general population [7].

Given the above facts, detecting DAN in patients with type 2 diabetes, especially when combined with CP, is of important diagnostic value for these patients. In this process, the study of the functional state of the upper abdominal organs, namely the biliary system, gastroesophageal area (with the focus on the gastric acid secretion can largely serve as one of the main elements for early diagnosis of digestive changes that can aggravate the clinical course of the existing pathology.

\section{THE AIM}

Aim of the research is to determine the peculiarities of changes in the gastric acid secretion against the background of diabetic autonomic neuropathy and autonomic dysfunction in patients with $\mathrm{CP}$ and type 2 diabetes. 
Table I. Evaluation of DAN indicators in the examined patients and the control group

\begin{tabular}{|c|c|c|c|c|}
\hline \multirow[b]{2}{*}{ Indicator } & \multirow{2}{*}{$\begin{array}{l}\text { Control group } \\
\qquad(n=20)\end{array}$} & \multicolumn{3}{|c|}{ Examined patients } \\
\hline & & $\begin{array}{l}\text { Group I } \\
(n=64)\end{array}$ & $\begin{array}{l}\text { Group II } \\
(n=40)\end{array}$ & $\begin{array}{c}\text { Group III } \\
(n=34)\end{array}$ \\
\hline Ewing test, beats/min & $21.71 \pm 3.15$ & $5.28 \pm 0.67^{*},++, \wedge$ & $8.67 \pm 0.88 *,++$ & $20.35 \pm 1.23$ \\
\hline $\begin{array}{c}\text { Shellong test, } \\
\text { mmHg }\end{array}$ & $6.78 \pm 1.45$ & $52.13 \pm 7.11 *,++, \wedge$ & $40.71 \pm 4.22{ }^{*},++$ & $7.88 \pm 1.25$ \\
\hline Test 30:15 & $2.38 \pm 0.27$ & $0.68 \pm 0.17 *,++$ & $0.92 \pm 0.15 *,+$ & $1.89 \pm 0.12$ \\
\hline
\end{tabular}

Note: between the indicators of the control group and the examined patients of Groups I, II and III the difference is statistically significant: ${ }^{*}$ - $p<0.01$; the difference between the indicators in patients of Group III and patients of Groups I and II is statistically significant: $+-p<0.05 ;++-p<0.01$; the difference between the indicators in patients of Group I and Group II is statistically significant: $\wedge$ - $p<0.05$.

\section{MATERIALS AND METHODS}

64 patients with $\mathrm{CP}$ and type 2 diabetes were examined and divided into the first group of the patients ( 35 male $(54.7 \%)$ and 29 female $(45.3 \%)$ of an average age of $48.9 \pm 6.3)$. Group II consisted of 40 patients with type 2 diabetes (22 men $(55.0 \%)$ and 18 women $(45.0 \%)$ at an average age of $48.9 \pm 6.3$ years); and Group III of the patients consisted of 34 patients with $\mathrm{CP}(21$ male $(61.8 \%)$ and 13 female (38.2\%) of an average age of $46.7 \pm 4.2$ years). All examined patients were either hospitalized in the Endocrinology and Gastroenterology Departments of Municipal Non Profit Enterprise "Transcarpathian Regional Clinical Hospital Named After Andrii Novak" of Transcarpathian Regional Council or were on outpatient observation by the district family doctors at the place of their residence.

The control group included 20 healthy individuals (11 male (55.0\%) and 9 female (45.0\%) of an average age of $45.2 \pm 5.1$ ).

All studies were performed with the consent of the patients, and their methodology was in line with the Helsinki Declaration of Human Rights of 1975 and its revision of 1983, the Council of Europe Convention on Human Rights and Biomedicine and the current legislation of Ukraine.

All patients were examined using general clinical, anthropometric, instrumental and laboratory research methods. All patients also underwent ultrasound examination of the abdominal cavity by conventional methods. Standard general and biochemical studies of blood serum were conducted with an emphasis on carbohydrate metabolism (glucose, glycated hemoglobin, insulin, C-peptide, proinsulin and glucose tolerance test).

The diagnosis of $\mathrm{CP}$ was established in accordance with the Marseille-Roman criteria (1989) with the addition of Ya.S. Zimmerman (1995) and clarifications of ICD-10. A coprological study was performed, serum amylase and fecal elastase-1 levels were determined, and ${ }^{13} \mathrm{C}$-mixed triglyceride $\left({ }^{13} \mathrm{C}\right.$-CTDT) and ${ }^{13} \mathrm{C}$-amylase respiratory tests $\left({ }^{13} \mathrm{C}\right.$-ADT $)$ were used to study the exocrine function of the pancreas,

Medical care was provided to the examined patients with diabetes according to the clinical protocols of the Ministry of Health of Ukraine and local protocols. The diagnosis of type 2 diabetes was established in accordance with the recommendations of the IDF (2005), as well as taking into account the criteria of a unified clinical protocol (The Ministry of Health of Ukraine Order of
21.12.2012 № 1118) [8, 9].The severity of type 2 diabetes was assessed by the level of HbA1c (Normal: up to 6.0\%).

To diagnose diabetic autonomic neuropathy (DAN), all patients underwent a cardiac rhythmogram (with Polar Pro heart rate monitor), during which heart rate was measured using a sensor that was applied to the chest over the projection of the apex of the heart, with the recording of heart contractions. Assessment of cardiovascular diabetic neuropathy was performed by standard Ewing tests (assessment of changes in heart rate (HR) with slow deep breathing ( 6 breaths per minute)); Shellong test (orthostatic test) and 30:15 test, as these tests are proposed as a standard for the diagnosis of DAN (San-Antonio, 1998).

Detection of autonomic dysfunction (AD) was performed using the O.M. Wayne's questionnaire (1998). The score above 15 indicated AD. Also, the Kérdöss Vegetative Index was calculated (KVI) on the basis of hemodynamic parameters (HR, blood pressure):

$\mathrm{KVI}=(1$-diastolic blood pressure $(\mathrm{DBP}) /$ pulse $){ }^{\star} 100$.

At full vegetative balance (eytonia) the index is in the range from -10 to +10 . With the predominance of sympathetic influences (sympathicotonia) the value of KVI will be higher than +10 , and with the predominance of parasympathetic influences (vagotonia) the value of KVI will be lower than -10 .

To study the gastric acid secretion of the stomach, patients underwent intragastric express $\mathrm{pH}$-metry, using a computer system according to the method of Prof. V.N. Chernobrovy. The study was conducted in the morning (7.00-9.00 hours). To accurately assess basal acidity 24 hours before the study, the use of any antacids was excluded.

Each patient was administered a $\mathrm{pH}$ microprobe through the mouth, the beginning of the $\mathrm{pH}$ measurement was carried out at the level of the transition of the esophagus into the stomach, which in most patients was $40 \mathrm{~cm}$ at the depth of the probe (from incisors). For the entire length of the stomach (from the cardia to the pylorus), the $\mathrm{pH}$ was measured every $1 \mathrm{~cm}$, each time for 15-20 seconds. The technique of basal topographic $\mathrm{pH}$-metry requires both the introduction and removal of the $\mathrm{pH}$ microprobe along the entire length of the stomach. There was a time interval of 5-10 minutes between the input and output of the probe. To evaluate the results, we took into account the functional $\mathrm{pH}$ interval/range (FI $\mathrm{pH})$ from 0 to 5 (in the direction of increasing gastric acidity): 
Table II. Indicators of the functional state of the ANS in the examined patients and the control group

\begin{tabular}{|c|c|c|c|c|}
\hline \multirow[b]{2}{*}{ Indicator } & \multirow[b]{2}{*}{$\begin{array}{l}\text { Control group } \\
(n=20)\end{array}$} & \multicolumn{3}{|c|}{ Examined patients } \\
\hline & & $\begin{array}{l}\text { Group I (CP+T2DM) } \\
\qquad(\mathrm{n}=64)\end{array}$ & $\begin{array}{c}\text { Group II } \\
\text { (T2DM) } \\
(n=34)\end{array}$ & $\begin{array}{l}\text { Group III } \\
\text { (CP) } \\
(n=40)\end{array}$ \\
\hline $\begin{array}{l}\text { Vegetative state according to } \\
\text { O.M.Wayne scale, points }\end{array}$ & $9.82 \pm 0.23$ & $55.71 \pm 3.23^{* *},+$ & $43.17 \pm 5.30^{* *},+$ & $28.74 \pm 2.50^{*}$ \\
\hline HR per minute & $70.40 \pm 3.82$ & $98.17 \pm 4.35^{*}$ & $89.56 \pm 4.89^{*}$ & $87.11 \pm 4.23^{*}$ \\
\hline $\mathrm{SBP}, \mathrm{mm} \mathrm{Hg}$ & $114.15 \pm 7.92$ & $158.26 \pm 5.54^{*}$ & $147.80 \pm 6.11$ & $130.42 \pm 5.34$ \\
\hline $\mathrm{DBP}, \mathrm{mm} \mathrm{Hg}$ & $74.72 \pm 5.81$ & $109.71 \pm 5.34^{*}$ & $98.11 \pm 3.90^{*}$ & $77.17 \pm 5.32$ \\
\hline KVI & $-6.55 \pm-0.44$ & $-13.70 \pm 1.89^{*},+, \wedge$ & $-10.78 \pm 1.25^{*},+, \wedge$ & $10.88 \pm 2.40^{*}$ \\
\hline
\end{tabular}

Note: between the indicators of the control group and the examined patients of Groups I, II and III the difference is statistically significant: ${ }^{*}-p<0,05$; $*^{*}-p<0.01$; the difference between the indicators in patients of Group III and patients of Groups I and II is statistically significant: $+-p<0,05 ;++-p$ $<0.01$; the difference between the indicators in patients of Group I and Group II is statistically significant: $\wedge-p<0,05$.

pH 7,0 - 7,5 (FI pH0 - anacidity);

pH 3,6 - 6,9 (FI pH1 - pronounced hypoacidity);

$\mathrm{pH} 2,3$ - 3,5 (FI pH2 - moderate hypoacidity);

pH 1,6 - 2,2 (FI pH3 - normal acidity);

$\mathrm{pH} 1,3$ - 1,5 (FI pH4 - moderate hyperacidity);

pH 0,9 - 1,2 (FI pH5 - pronounced hyperacidity).

According to the method of basal topographic $\mathrm{pH}$-metry, it is important to characterize the distribution of FI pH (in percent) over the entire length of the stomach, which included the individual functional maximum acidity of the stomach. On this basis, gastric acidity is divided into:

- minimal (up to $25 \%$ of the total number of $\mathrm{pH}$ measurements);

- selective (26-50\% of the total number of $\mathrm{pH}$ measurements); - absolute (51-75\% of the total number of $\mathrm{pH}$ measurements); - subtotal (76-99\% of the total number of pH measurements); - total ( $100 \%$ of $\mathrm{pH}$ measurements).

Criteria for exclusion of patients from the study were: type 1 diabetes, type 2 diabetes (severe with severe manifestations of diabetic angioneuropathy), active gastric and duodenal ulcers, erosive gastroduodenitis, gastroesophageal reflux disease, and the presence of Helicobacter pylori.

The analysis and processing of the results of the examination was carried out by means of the STATISTICA 10.0 computer program (StatSoft Inc., USA) using parametric and nonparametric methods for evaluating the results.

\section{RESULTS}

In all examined patients, the determination of DAN was performed according to the above methods. The results are presented in Table 1.

Evaluating the obtained data, DAN was detected in patients of Group I (patients with CP and type 2 diabetes) and Group II (patients with type 2 diabetes), as evidenced by a decrease in heart rate with slow deep breathing, which confirms the violation of parasympathetic innervation of the heart. Thus, this indicator was significantly lower in patients of Groups I and II, with a significant difference between these surveyed groups, i.e. worse indicators were observed in patients with $\mathrm{CP}$ and type 2 diabetes ( $5.28 \pm 0.67$ beats / $\mathrm{min})$ than in patients of Group II (type 2 diabetes without CP) $-8.67 \pm 0.88$ beats / min, respectively, $(\mathrm{p}<0.05)$. The result of this test was within normal limits in patients with $\mathrm{CP}$ and did not differ significantly from the control group. As for the results of the orthostatic test, this figure was increased in patients of Groups I and II. In addition, there was a significant difference between this indicator in patients with CP and those without CP - and amounted to 52.13 $\pm 7.11 \mathrm{~mm} \mathrm{Hg}$ and $40.71 \pm 4.22 \mathrm{~mm} \mathrm{Hg}$. correspondingly. This may indicate a violation of sympathetic innervation and, accordingly, DAN. Another diagnostic criterion for DAN is the 30:15 test. The indicators of this test were also significantly higher in patients of Groups I and II, while in patients with CP (group III), the indicators did not differ significantly from the control group.

The analysis of research on the definition of ANS dysfunction indicates its presence in the examined patients also mainly I and II groups according to the results of the questionnaire (O.M. Wayne questionnaire) and KVI. Indicators of the functional state of the autonomic nervous system (ANS) in the examined patients are presented in table 2 .

The analysis of the obtained clinical data indicates that the majority of examined patients of Groups I and II complained of frequent emotional stress, mood lability, increased irritability, anxiety, sleep disturbances, headache, fatigue, heart palpitations, and heart failure due to negative emotions. In addition, differences were found in assessing the degree of ANS dysfunction in the examined patients, namely - the most pronounced ANS dysfunction according to the Wayne questionnaire was diagnosed in patients with $\mathrm{CP}$ in combination with type 2 diabetes (group I) $-55.71 \pm$ 3.23 points, while patients of Group III (patients with CP) had the lowest values $(28.74 \pm 2.50$ points $)$ on this scale.

Further analysis of the indicators of the functional state of the ANS indicates the predominance of the influence of its parasympathetic division in patients of Groups I and II. It should be noted that according to the results of KVI statistically significant difference between the examined patients of Groups I and II was not established. In patients 
Table III. Characteristics of gastric acidity in the examined patients

\begin{tabular}{|c|c|c|c|}
\hline \multirow[b]{2}{*}{ Indicator } & \multicolumn{3}{|c|}{ Examined patients, \% } \\
\hline & $\begin{array}{c}\text { Group } \\
(\mathrm{n}=64)\end{array}$ & $\begin{array}{c}\text { Group } 2 \\
\text { (T2DM) } \\
(n=34)\end{array}$ & $\begin{array}{c}\text { Group } 2 \\
(C P) \\
(n=40)\end{array}$ \\
\hline Moderate hypoacidity: & $4.7 \% *$ & $11.7 \%$ & _ \\
\hline selective & $33.3 \% * *$ & - & - \\
\hline absolute & $66.7 \% *$ & $50.0 \%$ & - \\
\hline subtotal & _- & $50.0 \% * *$ & _- \\
\hline Normal acidity: & $21.9 \%$ * & $35.3 \%$ & $25.0 \%$ \\
\hline selective & $21.4 \%$ & $41.7 \%$ & $10.0 \%$ \\
\hline absolute & $35.7 \%+$ & $33.3 \%$ & $50.0 \%$ \\
\hline subtotal & $42.9 \%$ & $25.0 \%$ & $40.0 \%$ \\
\hline Moderate hyperacidity: & $42.2 \%$ & $32.4 \%$ & $45.0 \% *$ \\
\hline minimal & $3.7 \%$ & $18.2 \%$ & - \\
\hline selective & $7.4 \%$ & $36.4 \%$ & $27.8 \%++$ \\
\hline absolute & $22.2 \%$ & $27.2 \%$ & $33.3 \%$ * \\
\hline subtotal & $29.7 \%++$ & $18.2 \%$ & $16.7 \%$ \\
\hline total & $37.0 \%{ }^{* *},+$ & - & $22.2 \% * *$ \\
\hline Pronounced hyperacidity: & $31.2 \%$ * & $20.6 \%$ & $30.0 \%$ \\
\hline minimal & - & $42.8 \%$ & - \\
\hline selective & $20.0 \%$ & $28.6 \%$ & $25.0 \%$ \\
\hline absolute & $25.0 \%$ & $14.3 \%$ & $25.0 \%$ \\
\hline subtotal & $30.0 \%$ * & $14.3 \%$ & $33.3 \%$ * \\
\hline total & $25.0 \% * *$ & - & $16.7 \%$ * \\
\hline
\end{tabular}

Note: the difference between the indicators in patients of Group II and patients of Groups I and III is statistically significant: ${ }^{*}-p<0,05{ }^{* *}-p<0.01$; the difference between the indicators in patients of Group I and Group III is statistically significant: $\wedge$ - $p<0,05$.

of Group III (patients with CP) indicators of the functional state of the ANS indicates a slight predominance of the sympathetic division.

Analysis of gastric acid secretion indicates that no patients of Group III had normal acidity. Normal acidity is more often found in the second group of subjects (with type 2 diabetes). Both in patients with $\mathrm{CP}$ and type 2 diabetes, and in isolation with $\mathrm{CP}$, moderate hyperacidity was more often determined (in $42.2 \%$ of patients of I and $45.0 \%$ of patients of Group III). At the same time, in patients of Group I moderate hyperacidity was mostly total and subtotal, while in patients of Group III - more often selective and absolute. Severe hyperacidity is also more common in $\mathrm{CP}$ and in patients with a combination of $\mathrm{CP}$ and type 2 diabetes. In patients of Group I, pronounced hyperacidity was more often subtotal, total and absolute, and in patients of Group III - total, absolute and selective hyperacidity were more often diagnosed. Patients of Group II (patients with type 2 diabetes) are more likely to have normal acidity and moderate hyperacidity.

It should be noted that in characterizing the clinical manifestations of gastric dyspepsia, such signs as heartburn, acid regurgitation and epigastric pain occurred only among the examined Group III. In patients of the Groups I and II signs of biliary dyspepsia (bitter taste in the mouth, belching with bitter aftertaste), and also heaviness mainly in the right upper quadrant came to the fore.

\section{DISCUSSION}

Diabetic autonomic neuropathy (DAN) is a serious and common complication of diabetes, often overlooked and misdiagnosed. Diabetic autonomic neuropathy may involve the cardiovascular, genitourinary, and the neuroendocrine systems as well as the upper and lower gastrointestinal (GI) tract. Abnormalities of GI function in diabetics are thought to be related, at least in part, to autonomic neuropathy [10].

Our studies indicate that in patients with type 2 diabetes, especially in combination with $\mathrm{CP}$, there is an impairment of gastric acid secretion, which is mainly manifested by hyperacidity. However, in these patients symptoms of gastrointestinal lesions are not pronounced against the background of DAN and autonomic disorders, and this in many respects complicates timely diagnosis and adequate pathognetically substantiated treatment.

The professional literature discusses the violation of the acid-forming function of the stomach, mainly in the defeat of the upper gastrointestinal tract and in its combination with other pathological conditions. Skubytska LD, Severynovska OV (2015) indicate the dependence of 
the values of gastric juice acidity on the digestive function of the alimentary tract in the diseased with several pathologies - chronic gastritis and with accompanying pancreas affection - has been investigated. The decrease of acid production of the stomach in the diseased I (chronic gastritis) and the diseased II (chronic gastritis with pancreas affection) has been detected, with more noticeable effect in the group with accompanying pathology [11].

Therefore, further study of gastric acid secretion, as well as the influence of DAN on its production against the background of autonomic disorders in patients with $\mathrm{CP}$ and type 2 diabetes has important diagnostic value in these patients for the selection of adequate treatment. Further research should also be conducted in this direction to reveal the relationship between DAN and digestive tract lesions, including $\mathrm{CP}$ in patients with type 2 diabetes.

\section{CONCLUSIONS}

1. Ewing, Shellong and 30:15 tests are effective methods for detecting DAN in patients with CP and type 2 diabetes.

2. The predominance of the parasympathetic division of the ANS, as well as manifestations of severe ANS dysfunction, are observed in patients with $\mathrm{CP}$ and type 2 diabetes.

3 . The prevalence of gastric hyperacidity on the background of DAN was established in patients with $\mathrm{CP}$ and type 2 diabetes. In this case, the absence of clinical symptoms or their minimal severity is determined, which indicates the lesion of the digestive tract in these patients.

\section{REFERENCES}

1. Fadejenko G.D., Chernishov V.A. Defeat of the gastroduodenal area in patients with diabetes mellitus: clinical and population aspects. Medicine of Ukraine. 2011; 7(153): 48-50. (in Ukranian).

2. Larin A.S., Tkach S.M. Patogenetocheskaja rol kisechnogodisbioza $v$ razvitii ozhirenia, insulinorezistentnosti I sacharnogo diabeta 2 tipa [Pathogenetic role of kissechnydysbiosis in the development of obesity, insulin resistance and type 2 diabetes mellitus]. Health of Ukraine. Thematic number. Gastroenterology. Hepatology. Coloproctology. 2016; 2(40): 20-21. (in Russian).

3. Babinec L.S., Zacharchuk U.M., Pidruchna S.R. Zastosuvanja balnoji sistemi M-ANNHEIM pri chronichnomu pancreatiti u komorbidnosti z cukrovim diabetom v ambulatornij practici [The use of the M-ANNHEIM score system for chronic pancreatitis in comorbidity with diabetes mellitus in outpatient practice]. Thematic number. Gastroenterology. Hepatology. Coloproctology. 2016; 2(40): 54-55. (in Ukrainian).

4. Babinec L.S., Palihata M.V., Sasik G.M. Possibilities of complex rehabilitation of patients with chronic pancreatitis at the stage of primary care (literaturereview). Pancreatology Club Bulletin. 2018: 4-11.(in Ukrainian).

5. Raksha N.G., Halenova T.I.,Vovk T.B. et al. Proteolitic imbalance as a key factor of the development of chronic pancreatitis with and without type 1 diabetes mellitus. Visnik problem biologiii medicine. 2019; 3 (152): 186-191. (in Ukrainian) DOl 10.29254/2077-4214-2019-3-152-186-191

6. Hristich T.M., Hontsariuk D.0. Etiological factors which from the chronical pancreatitis. Zdobutkiklinichnoji I eksperimentalnoji medicine. 2018;3:20-27. (in Ukrainian). doi: 10.11603/1811-2471.2018. v0.i3.9221.
7. Skrypnyk N.V., Gryb V.A., Didushko 0.M. Features of the Pathogenesis and Treatment of Diabetic Autonomic Neuropathy (Literature Review). Medicine of Ukraine. 2012; 2 (158): 6-14. (in Ukrainian).

8. Hobzej M.K., Guljchij M.V., Manyjkovskij B.M. Type 1 Diabetes Mellitus in joung people and adults. Unified clinical protocol for primary, emergency, secondary (specialized) and third (highly specialized) medical care. Kyiv; 2014, 71 p. (in Ukrainian).

9. Hobzej M.K., Guljchij M.V., Stepanenko A.V. Type 2 Diabetes Mellitus. Unified clinical protocol for primary and secondary (specialized) medical care. Kyiv; 2012, 118p. (in Ukrainian).

10. Verrotti A., Prezioso G., Scattoni R., Chiarelli F. Autonomic Neuropathy in Diabetes Mellitus. Front. Endocrinol. (Lausanne). 2014; 5: 205.

11. Skubytska L.D., Severynovska 0.V. Acid-marking function of stomach with chronic gastritis and chronic gastritis with accompanying pancreas affection. Word of Medicine and Biology. 2014; 4 (54): 69-73.

Authors are responsible for the content and it does not necessarily represent the official views of the National Institutes. The scientific research was carried out within the scientific research work framework №851 "Mechanisms of the formation of complications in liver diseases and pancreas, methods of their treatment and prevention" (state registration number: 0115U001103), as well as the general department topic of the department of propaedeutics of internal diseases, as well as the scientific topic of the Department of Propaedeutics of Internal Medicine (Polymorbid pathology in diseases of the digestive system, features of pathogenesis, the possibility of correction (state registration number 0118U004365).

\section{ORCID and contributionship:}

Yelyzaveta S. Sirchak: 0000-0001-6738-0843 ${ }^{A, B, C, D}$

Vasilij Ye. Barani: 0000-0002-2616-2230 C,D

Olena M. Odoshevska: 0000-0003-3412-3554 E,F

Oksana I. Petrichko: 0000-0001-5420-6424 ${ }^{\mathrm{E}}$

\section{Conflict of interest:}

The Authors declare no conflict of interest.

\section{CORRESPONDING AUTHOR Yelyzaveta S. Sirchak \\ Uzhhorod national university \\ 3 Narodna sqr., 88000 Uzhhorod, Ukraine \\ tel: +380509761794 \\ e-mail:sirchakliza777@gmail.com}

Received: 09.11 .2020
Accepted: 02.03 .2021

A - Work concept and design, B - Data collection and analysis, C - Responsibility for statistical analysis, D-Writing the article, $\mathbf{E}$-Critical review, $\mathbf{F}$ - Final approval of the article 